\title{
Effect of A-nor steroids and oestradiol on progesterone production by human luteal cells
}

\author{
Wang Han-zheng, Lu Shu-hua*, Shen Wei-xiong, Sun Zhi-da, Zhou Wei, \\ Wu Yu-fen† and Zhou Mei-rong*
}

Shanghai Institute of Planned Parenthood Research, *Shanghai Lu-wan District Maternity and Child Health Hospital and $\dagger$ Ren-jin Hospital, Shanghai No. 2 Medical University, Shanghai, China

\begin{abstract}
Summary. Cell suspensions were prepared from human corpora lutea obtained during the mid-luteal phase. Progesterone production was assessed after short-term incubation of luteal cell suspensions. Luteal cells were very sensitive to hCG, the concentration required for $50 \%$ maximum response being $0.01 \mathrm{i} . \mathrm{u} . / \mathrm{ml}$, and the response was 5 times higher than the basal production.

Oestradiol $(1-100 \mu \mathrm{M})$ induced a significant dose-related decrease in both basal and hCG-stimulated progesterone production. The A-nor steroidal compounds anordrin and AF-45 reduced hCG-stimulated progesterone production only at the high concentration of $100 \mu \mathrm{M}$. The $\mathrm{ED}_{50}$ values were approximately $3 \mu \mathrm{M}, 75 \mu \mathrm{M}$ and $100 \mu \mathrm{M}$ for oestradiol, AF-45 and anordrin respectively. Anordrin showed no significant effects on basal progesterone production. In addition, oestradiol markedly inhibited the activity of $3 \beta$-hydroxysteroid dehydrogenase in luteal cells, expressed by the conversion of pregnenolone to progesterone, but the inhibitory effects of anordrin and AF-45 were negligible or relatively low.

The effects of anordrin and AF-45 were different from those of oestradiol on progesterone production by human luteal cells in vitro, indicating that neither substance is likely to be a useful luteolytic agent in women.
\end{abstract}

Keywords: A-nor steroid; oestradiol; luteal cells; progesterone; $3 \beta$-hydroxysteroid dehydrogenase; man

\section{Introduction}

Anordrin (an A-nor steroidal compound) is used as a vacation pill for women in China. It is also well documented that anordrin has potent antifertility effects in rabbits, rats, mice and hamsters (Gu et al., 1980). However, the pharmacological action of anordrin is unknown. The relationship between its oestrogenicity and its antiprogesterone action has been the subject of debate (Liu et al., 1985). Although anordrin has been reported to reduce the serum progesterone concentrations in rats and rabbits $(\mathrm{Gu}, 1984)$, equivalent data for man are scarce. AF-45 is also an A-nor steroidal compound. The only difference in structural formula between anordrin and AF-45 is that the former is the dipropionate of AF-45. Pincus et al. (1964) investigated the mechanism of the anti-implantation effect of AF-45 (named compound $V$ in his paper) in rats and mentioned its oestrogenicity in women (Pincus, 1967).

Oestradiol is a potent luteolytic agent in rhesus monkeys when administered systemically (Laherty et al., 1985) and when injected into the corpus luteum (Karsch et al., 1978). It also inhibited progesterone secretion by dispersed human luteal cells (Williams et al., 1979). Due to the marked species differences in the factors which control luteal regression, it is appropriate to investigate the direct effects of steroids on human luteal cells. The present studies were designed to compare the inhibitory potency of oestradiol, anordrin and AF-45 on both the basal and hCG-stimulated progesterone 
<smiles>C#C[C@H]1CC2C3CCC4CC(O)(C#C)CC4(C)C3CCC2(C)C1O</smiles>

Fig. 1. The chemical structures of anordrin and AF-45.

production by dispersed human luteal cells. The possible effects on $3 \beta$-hydroxysteroid dehydrogenase ( $3 \beta-H S D)$ were also investigated.

\section{Materials and Methods}

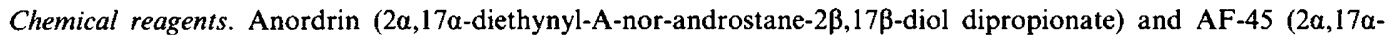
diethynyl-A-nor-androstane-2 $\beta, 17 \beta$-diol) were synthesized by Dr Li Rei-lin in the Shanghai Institute of Planned Parenthood Research. The chemical structures are shown in Fig. 1. Oestradiol, collagenase type 1 and DNase were purchased from Sigma Chemical Company (Poole, Dorset, U.K.) and protease Grade 11 from Boehringer Mannheim GmbH (Mannheim, W. Germany). Purified hCG (5380 i.u./mg) was a gift from Shanghai Biochemical and Pharmaceutical Laboratories (Shanghai, China).

Patients. Biopsies of corpora lutea were obtained at laparotomy from women aged between 32 and 45 years, who had normal menstrual cycles, and were undergoing hysterectomy for a variety of non-malignant conditions. All had given consent in accordance with a procedure approved by the ethical committee of the hospital and local Public Health Authorities. The corpora lutea included in this study were assessed as being mid-luteal phase (Day 19-23) as determined from the time of the last menstrual period. After removal, the luteal tissues were placed in ice-cold modified Eagle's medium from Nissui Seiyaku Co. (Tokyo, Japan), containing $20 \mathrm{~mm}$-Hepes buffer and transported immediately to the laboratory.

Cell dispersion and incubation. A cell suspension was prepared from each corpus luteum as follows. Each tissue sample was minced and then dispersed in modified Eagle's medium containing $0.2 \%$ collagenase, $0.1 \%$ protease, $0.02 \%$ DNase and $2 \%$ calf serum at a concentration of $100 \mathrm{mg}$ tissue/ml digestion medium and incubated at $37^{\circ} \mathrm{C}$ in a shaking water bath.

After $45-60 \mathrm{~min}$, the released cells were filtered through nylon gauze $(75 \mu \mathrm{m}$ mesh), washed, centrifuged $(150 \mathrm{~g}$, $10 \mathrm{~min}$ ) and resuspended in culture medium. The cell suspension was examined and counted under the light microscope in the presence of methylene blue $(0.01 \% \mathrm{w} / \mathrm{v})$. The viability of the dispersed cells was $75-85 \%$ as judged by trypan blue exclusion (Tennant, 1964).

After a preincubation for $1 \mathrm{~h}$ at $37^{\circ} \mathrm{C}$, the cell suspension was centrifuged, washed and rediluted with culture medium. Then approximately $1-1.5 \times 10^{5}$ cells $(0.3 \mathrm{ml}$ cell suspension) were dispensed to each tube and incubated with various hormonal additions for a further $3 \mathrm{~h}$. All compounds added to the cell suspension were diluted in culture medium. The addition volume was $30 \mu \mathrm{l}$. HCG was diluted in culture medium before incubation. The test steroids were dissolved in polyethylene glycol and ethanol $(50: 50 \mathrm{v} / \mathrm{v})$ and then diluted serially with culture medium before addition to the luteal cells. Each control tube contained $1-1.5 \times 10^{5}$ cells in $0.3 \mathrm{ml}$ culture medium. To each of these was added the same volume of the polyethylene glycol:ethanol mixture $(50: 50 \mathrm{v} / \mathrm{v})$ as had been used for steroids. After incubation, the cell suspension samples were stored at $-20^{\circ} \mathrm{C}$ until steroid radioimmunoassay.

Radioimmunoassay of progesterone. Progesterone in each incubate (including cells and medium), was extracted with $2 \times 5 \mathrm{ml}$ ether and then assayed using a validated RIA according to the protocol in the WHO Manual (1986). The specific antiserum was provided by the Shanghai Institute of Biological Products (Shanghai, China). The crossreactivity of the antiserum against progesterone at $50 \%$ displacement was as follows: pregnenolone $0.018 \%, 17 \alpha$ hydroxyprogesterone $1.6 \%$, testosterone $0.09 \%$, oestradiol $<0.001 \%$, anordrin $<0.001 \%$, AF. $45<0.001 \%$, and dihydrotestosterone $<0.001 \%$. The sensitivity of the assay, defined as the minimum detectable amount, was $0.039 \mathrm{pmol} /$ tube. Within- and between-assay coefficients of variation were $8 \%$ and $15 \%$ respectively. Progesterone concentrations were normalized to $1 \times 10^{5}$ cells/incubation. The values calculated for progesterone production relate to synthesis rather than cellular release because 'cells plus medium' were extracted before assay.

The basal progesterone production was estimated by the $37^{\circ} \mathrm{C}$ incubation in the absence of hCG. The inhibitory potencies of the test steroids were determined by comparing the $\mathrm{ED}_{50}$ values, i.e. the concentration of the test steroid causing a $50 \%$ decrease of progesterone production. The amount of progesterone in the presence of $1 \mathrm{i} . \mathrm{u} . \mathrm{hCG} / \mathrm{ml}$ was taken as $100 \%$. The significance of difference in progesterone values between sets of incubates were calculated by using paired Student's $t$ tests. 


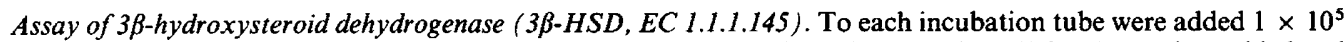
dispersed luteal cells and one of the test steroids at various concentrations. Pregnenolone $(1.0 \mu \mathrm{M})$ was then added and the incubation carried out at $37^{\circ} \mathrm{C}$ for $30 \mathrm{~min}$. All experiments were performed in duplicate. The inhibitory effects of $3 \beta$-HSD were expressed as the reduction in the conversion of pregnenolone to progesterone. The average rate of formation of progesterone was compared with that of the controls which was taken as $100 \%$ (Shinada et al., 1978). The time course of the effect of the different steroids on the conversion of pregnenolone to progesterone was also studied. After intervals of 10,20 and $30 \mathrm{~min}$, the incubations were terminated by placing the tubes in an ice bath, followed by freezing at $-20^{\circ} \mathrm{C}$. The progesterone content was then assayed as described above.

\section{Results}

\section{Responsiveness of dispersed luteal cells}

As shown in Fig. 2, basal progesterone production was relatively low in the absence of gonadotrophin and the rate was generally constant during the 3-h incubation. Addition of hCG (1 i.u./ml) caused a rapid increase of progesterone production which slowed down during the third hour (Fig. 2). Figure 3 shows the responses of the luteal cells to different concentrations of hCG. The minimum effective dose of hCG was $0.01 \mathrm{i} . \mathrm{u} . / \mathrm{ml}$ and 1 i.u. hCG $/ \mathrm{ml}$ was sufficient to elicit maximum steroidogenesis.

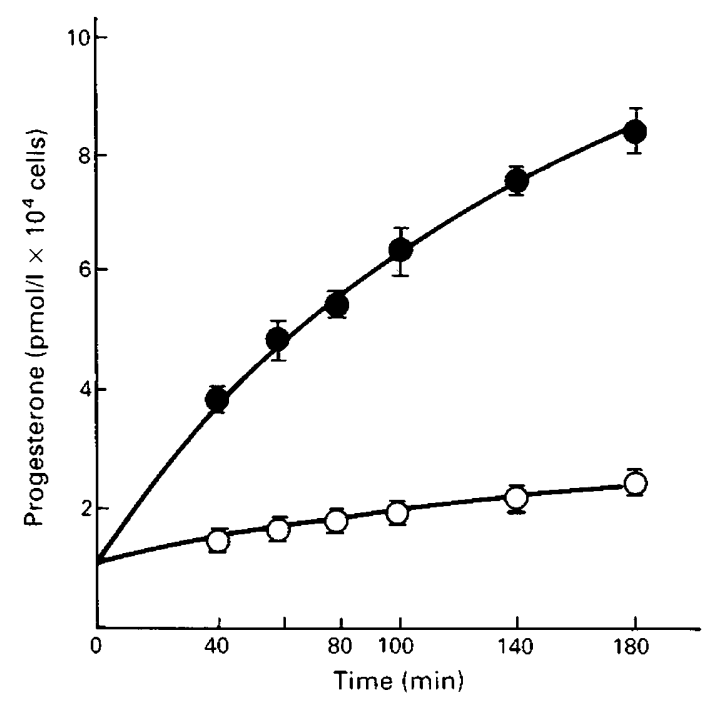

Fig. 2. Time course for progesterone production by dispersed luteal cells from human corpora lutea of the mid-luteal phase. Cells were incubated in the presence $(\bullet)$ and absence $(O)$ of hCG $(1 \mathrm{i} . \mathrm{u} . / \mathrm{ml})$ at $37^{\circ} \mathrm{C}$ in $95 \% \mathrm{O}_{2}: 5 \% \mathrm{CO}_{2}$. Values represent the mean \pm s.e.m. of triplicate incubates.

\section{Effects of oestradiol, anordrin and $A F-45$}

Figure 4 shows that, in the presence of hCG, oestradiol markedly inhibited progesterone production at concentrations ranging from 1.0 to $10 \mu \mathrm{M}(P<0.001)$. The inhibition was dose-related. When anordrin and AF-45 were present at $10 \mu \mathrm{M}$, only a slight decline of progesterone production was observed $(P>\mathbf{0 . 0 5})$, but a significant decrease was found at the higher concentration of $100 \mu \mathrm{M}$. The doses of oestradiol, AF-45 and anordrin that inhibited progesterone production by $50 \%\left(\mathrm{ED}_{50}\right)$ were about $3 \mu \mathrm{M}, 75 \mu \mathrm{M}$ and $100 \mu \mathrm{M}$ respectively. Anordrin appeared to be the least inhibitory. 


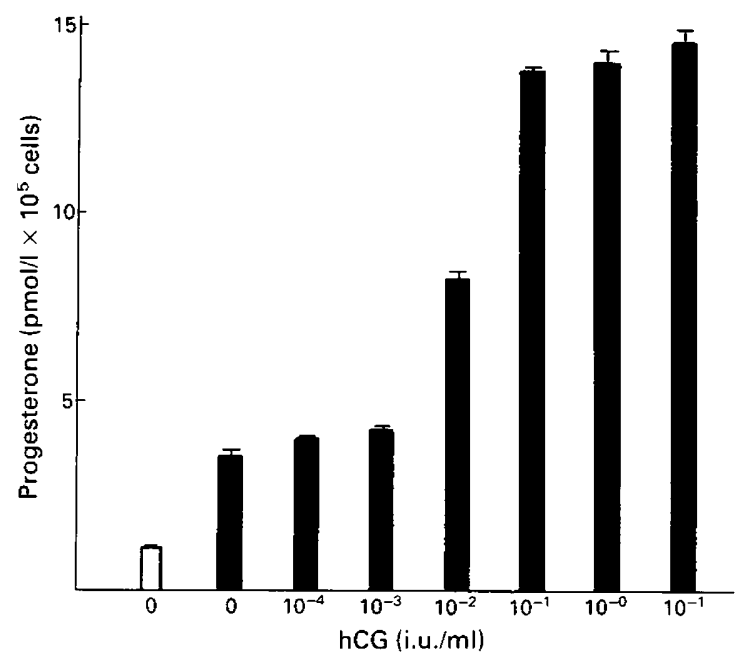

Fig. 3. Effect of hCG on progesterone production by dispersed human luteal cells incubated for $3 \mathrm{~h}$ at $37^{\circ} \mathrm{C}$ in $95 \% \mathrm{O}_{2}: 5 \% \mathrm{CO}_{2}$. Values represent the mean \pm s.e.m. of triplicate incubates. The open bar indicates the progesterone concentration before incubation.

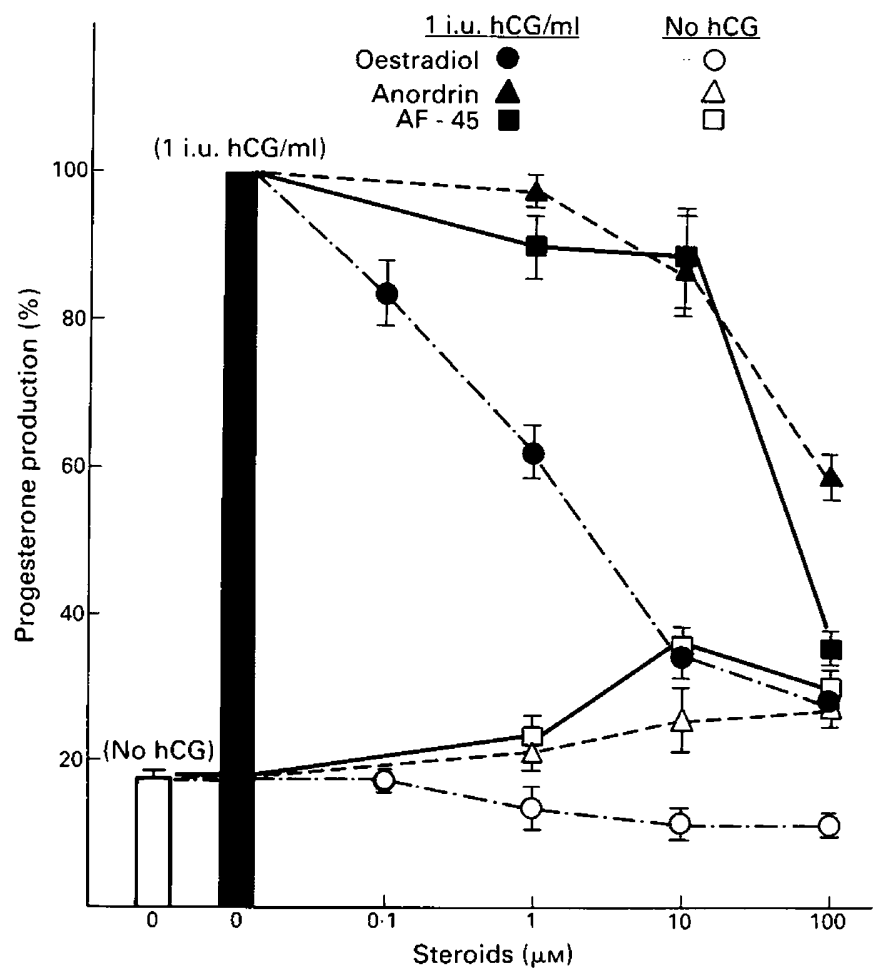

Fig. 4. The inhibitory effects of oestradiol, anordrin and AF-45 on progesterone production by dispersed human luteal cells incubated for $3 \mathrm{~h}$ at $37^{\circ} \mathrm{C}$ in the presence or absence of $1 \mathrm{i} . \mathrm{u}$. hCG $/ \mathrm{ml}$. Values represent the mean \pm s.e.m. of 3 separate experiments, each in triplicate incubates. 


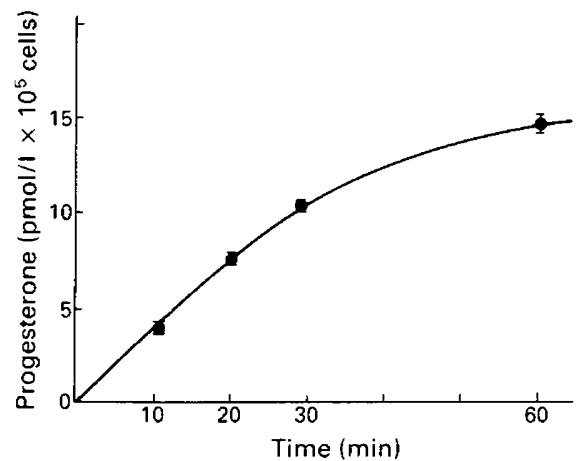

Fig. 5. Effect of time on the conversion of pregnenolone $(1 \mu \mathrm{M})$ into progesterone by dispersed human luteal cells incubated at $37^{\circ} \mathrm{C}$. Values represent the mean and range of duplicate incubates.

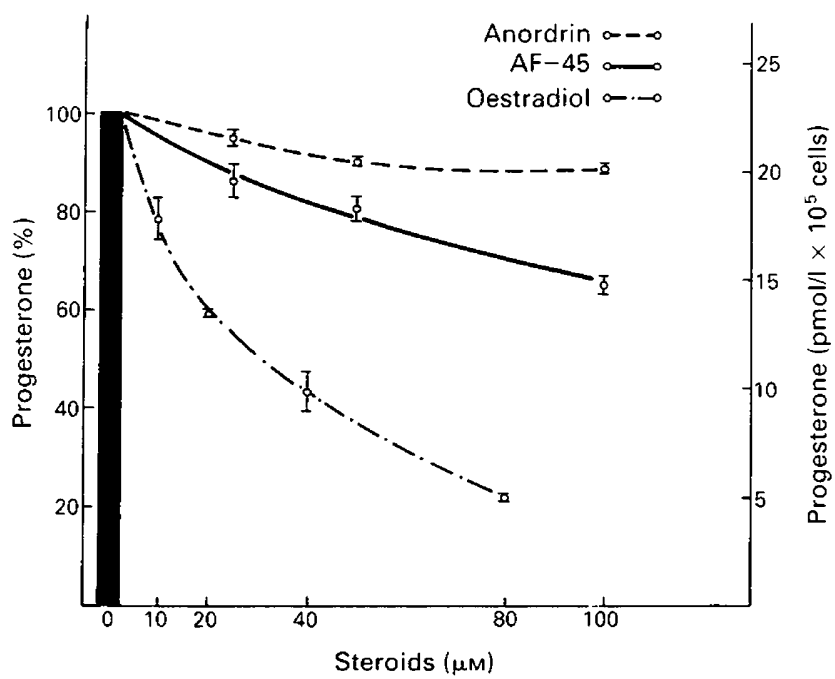

Fig. 6. The inhibition of conversion of pregnenolone $(1 \mu \mathrm{M})$ to progesterone by oestradiol, anordrin and AF-45 in dispersed human luteal cells $\left(1 \times 10^{5} /\right.$ tube $)$, incubated for $30 \mathrm{~min}$. Values represent the mean \pm s.e.m. of triplicate incubates.

Figure 4 also shows that, in the absence of hCG, oestradiol reduced the basal progesterone production, but there was no inhibition by AF-45 and anordrin. In several experiments when AF45 or anordrin were added, a slight increase of the basal progesterone concentrations was found, although the difference was not statistically significant.

\section{Effects on 3 $\beta$-hydroxysteroid dehydrogenase}

The transformation of pregnenolone into progesterone was linear with $1 \times 10^{5}$ luteal cells/tube up to $30 \mathrm{~min}$ of incubation (Fig. 5). Figure 6 shows that oestradiol was a potent inhibitor of $3 \beta$ HSD, inducing a dose-related inhibition of transformation of pregnenolone into progesterone in

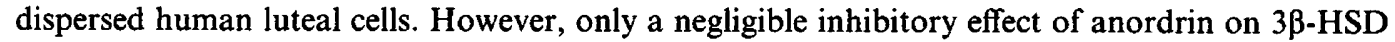
activity could be observed within $30 \mathrm{~min}$, even at high concentration. AF- 45 reduced the conversion rate to $63 \%$ at the high concentration of $100 \mu \mathrm{M}$. 


\section{Discussion}

The human luteal tissues obtained at laparotomy appeared to function normally in vitro, showing a dose-related response to hCG in producing progesterone. As reviewed by diZerega \& Hodgen (1980), primate luteal tissue responds in vivo to hCG with an increase in progesterone secretion. Dispersed human luteal cells respond in vitro to hCG with a significant increase in progesterone secretion into the medium (Biggs \& Baker, 1978). The reported sensitivity of luteal cells to hCG varies. A minimal effective dose of 0.1 i.u. hCG $/ \mathrm{ml}$ increased progesterone production in the studies by Maeyama $e t$ al. (1976), but 1 i.u./ml was the effective dose found by Tan et al. (1982). Richardson \& Masson (1980) reported that dispersed human luteal cells showed a submaximal response to a concentration of $0 \cdot 1 \mathrm{i} . \mathrm{u}$. hCG $/ \mathrm{ml}$. In the present study, the dose of hCG inducing a submaximal response was 0.01 i.u./ml, with maximal stimulation at $0.1-10 \mathrm{i} . u$. $/ \mathrm{ml}$, which was obviously lower than that found by Maeyama et al. (1976). The factors responsible for the greater sensitivity could be the prolongation of preincubation to $1 \mathrm{~h}$ in our experiments. It might also be due to the potency of the hCG preparation. The dispersed preparation used in the present study is useful for the examination of human luteal function.

Oestradiol inhibits progesterone secretion when administered systemically to monkeys (Karsch et al., 1978). Stouffer (1977) observed that $1 \mu \mathrm{g}$ oestradiol $/ \mathrm{ml}$ significantly inhibited progesterone production by mid-luteal phase cells and that late-luteal phase cells were inhibited by $0.1 \mu \mathrm{g}$ oestradiol $/ \mathrm{ml}$. Laherty et al. (1985) demonstrated signficant depression of hLH-stimulated progesterone production by using lower doses of oestradiol $(0 \cdot 1-10 \mathrm{ng} / \mathrm{ml})$ in monkey luteal tissues. It seems that luteal tissues of monkeys are much more sensitive to oestradiol inhibition than are those of human. Williams et al. (1979) have shown a direct inhibition by oestradiol at doses ranging from 0.1 to $10 \mu \mathrm{g} / \mathrm{ml}$ on hCG-stimulated progesterone production by dispersed human luteal cells. Our results are consistent with those of previous studies: oestradiol has a direct inhibitory effect upon progesterone production by human luteal tissue in vitro.

The intracellular mechanism for the observed inhibitory action of oestradiol on basal and hCGstimulated progesterone production by monkey and human luteal cells in culture is not clear (Richardson, 1986). The possibility that oestradiol-induced luteolysis may be mediated by PGF-2 $\alpha$ does not appear to operate in human luteal cells (Thibier et al., 1980). It has been suggested that the site of action of oestradiol may be after the accumulation of cAMP (Williams et al., 1979). Oestradiol may also inhibit the activity of $\Delta^{5} 3 \beta$-hydroxysteroid dehydrogenase- $\Delta^{5.4}$-isomerase (Depp et al., 1973). In the present study, oestradiol certainly acted as a potent inhibitor of $3 \beta-H S D$ in human luteal cells in vitro.

Gu et al. (1980) observed that anordrin could decrease plasma progesterone concentrations and shorten the luteal periods of treated women, thus indicating some effect on corpus luteum function. Our short-term studies are not directly comparable with those in-vivo studies, but our results indicate that anordrin would not be a useful luteolysin.

After further investigation, Gu et al. (1984) have suggested that anordrin is hydrolysed to AF-45 which is the active substance in vivo. In our in-vitro study, when anordrin was added directly into luteal cell suspensions, we found that the inhibitory potency of anordrin was actually much weaker than that of AF-45. Therefore, if anordrin were not hydrolysed or converted to other compounds by organs such as the liver or gut, it could not effectively decrease the plasma progesterone concentrations of treated women.

The relationship between the oestrogenic and the antiprogestagenic activities of anordrin has been the subject of debate (Liu et al., 1985). In this study, anordrin showed different characteristics in comparison with oestradiol with respect to their effects on progesterone production. Although anordrin did cause an increase in basal progesterone production, no significant dose-related effects could be found when anordrin was used at doses of 1 to $100 \mu \mathrm{M} / \mathrm{ml}$ and the inhibitory effect of anordrin on $3 \beta$-HSD was negligible. $\mathrm{Gu}$ (1984) suggested that the free hydroxyl radicals in the $17 \beta$ - and $2 \beta$ position were essential for binding to oestradiol receptors, but there is no free hydroxyl in the structure 
of anordrin (Fig. 1), and so the oestrogenicity of the substance might not be the factor that gives its antifertility effects. The basic mechanism of the antifertility action of anordrin remains to be elucidated.

This study received financial support from Shanghai Municipal Commission of Family Planning and the Special Programme of Research in Human Reproduction of the World Health Organization. We thank Dr J. K. Findlay and Dr J. R. Clarke for help and encouragement.

\section{References}

Biggs, J.S.G. \& Baker, T.G. (1978) Hormone production by the intact human corpus luteum in vitro.J. Reprod. Fert. 54, 221-225.

Depp, R., Cox, D.W., Pion, R.J., Conrad, S.H. \& Heinrichs, W.L. (1973) Inhibition of the pregnenolone $\Delta^{5}-3 \beta$-hydroxysteroid dehydrogenase- $\Delta^{5.4}$ isomerase systems of human placenta and corpus luteum of pregnancy. Gynaec. Invest 4, 106-120.

diZerega, G.S. \& Hodgen, G.D. (1980) Changing functional status of the monkey corpus luteum. Biol. Reprod. 23, 253-263.

Gu, X.G. (1984) Antifertility effect of anordrin in rabbits with reference to progesterone and estrogen level. Acta physiol. sinica 36, 573-577.

Gu, Z.P., Wang, W.C., Lu, R.F. \& Jiang, X.J. (1980) Plasma progesterone levels in normal and pregnant Chinese women and effect of contraceptives on them. Chin.med.J. 93, 523-527.

Gu, Z.P., Zhu, D.Y., Qi, L.M. \& Shen, P.J. (1984) Studies on the anti-fertility effect of anordrin and its analogues. Acta physiol. sinica 36, 611-613.

Karsch, F.J., Kley, L.C., Weik, R.F., Dierschke, D.J. \& Knohil, E. (1978) Functional luteolysis in the rhesus monkey: the role of estrogen. Endocrinology 92, $1148-1152$.

Laherty, R.F., Rotter, D., Yamamoto, M. \& Jaffe, R.B. (1985) Effects of oestradiol and prolactin on progesterone production by rhesus monkey luteal cells in vitro. Acta endocr., Copenh. 108, 266-272.

Liu, C.Q., Chen, B.L., Shen, S.R., Zhang, G.Z. \& Dai, M.Z. (1985) Effects of anordrin and its analogues on antifertility. Contraception 32, 301-307.

Maeyama, M., Saita, B., Ichihara, K., Munemura, M. \& Mori, N. (1976) Effects of prostaglandin $E_{2}$ on adenosine $3^{\prime}, 5^{\prime}$-monophosphate accumulation and progesterone syntheses in human corpora lutea in vitro. J. Steroid Biochem. 7, 295-300.

Pincus, G. (1967) Control of fertility in mammals by hormonal steroids. Anat.Rec. 157, 53-61.
Pincus, G., Banik, U.K. \& Jacques, J. (1964) Further studies on implantation inhibitors. Steroids 4, 657-676.

Richardson, M.C. (1986) Hormonal control of ovarian luteal cells. Oxford Rev. Reprod. Biol. 8, 342-346.

Richardson, M.C. \& Masson, G.M. (1980) Progesterone production by dispersed cells from human corpus luteum: stimulation by gonadotrophins and prostaglandin $F 2 \alpha$, lack of response to adrenaline and isoprenaline. J.Endocr. 87, 247-254.

Shinada, T., Yokota, Y. \& Igarashi, M. (1978) Inhibitory effect of various gestagens upon the pregnenolone $3 \beta$-aldehydrogenase-5,4-isomerase system in human corpora lutea of menstrual cycles. Fert. Steril. 29, 84-87.

Stouffer, R.L., Nixon, W.E. \& Hodgen, G.D. (1977) Estrogen inhibition of basal and gonadotropinstimulated progesterone production by rhesus monkey luteal cells in vitro. Endocrinology 101, 1157-1163.

Tan, G.J.S., Tweedale, R. \& Biggs, J.S.G. (1982) Oxytocin may play a role in the control of the human corpus luteum. J. Endocr. 95, 65-70.

Tennant, J.R. (1964) Evaluation of the trypan blue technique for the determination of cell viability. Transplantation 2, 685-694.

Thibier, M., El-Hassan, X., Clark, M.R., LeMaire, W.J. \& Marsh, J.M. (1980) Inhibition by oestradiol of human chorionic gonadotropin-induced progesterone accumulation in isolated human luteal cells: lack of mediation by prostaglandin. J. clin. Endocr. Metab. 50, 590-592.

Williams, M.T., Roth, M.S., Marsh, J.M. \& LeMaire, W.J. (1979) Inhibition of human chorionic gonadotropin induced progesterone synthesis by oestradiol in isolated human luteal cells. J. clin. Endocr. Metab. $48,437-440$.

Received 12 October 1987 